\title{
Risk factors, host response and outcome of hypothermic sepsis
}

\author{
Maryse A. Wiewel ${ }^{1 \dagger}$, Matthew B. Harmon ${ }^{2^{*} \dagger}$, Lonneke A. van Vught ${ }^{1}$, Brendon P. Scicluna', Arie J. Hoogendijk', \\ Janneke Horn' ${ }^{2}$, Aeilko H. Zwinderman ${ }^{3}$, Olaf L. Cremer ${ }^{5}$, Marc J. Bonten ${ }^{6,7}$, Marcus J. Schultz ${ }^{2}$, Tom van der Poll ${ }^{1,4}$, \\ Nicole P. Juffermans ${ }^{2 \dagger}$ and W. Joost Wiersinga ${ }^{1,4+}$
}

\begin{abstract}
Background: Hypothermia is associated with adverse outcome in patients with sepsis. The objective of this study was to characterize the host immune response in patients with hypothermic sepsis in order to determine if an excessive anti-inflammatory response could explain immunosuppression and adverse outcome. Markers of endothelial activation and integrity were also measured to explore potential alternative mechanisms of hypothermia. Finally we studied risk factors for hypothermia in an attempt to find new clues to the etiology of hypothermia in sepsis.

Methods: Consecutive patients diagnosed with sepsis within 24 hours after admission to ICUs in two tertiary hospitals in the Netherlands were included in the study $(n=525)$. Hypothermia was defined as body temperature below $36{ }^{\circ} \mathrm{C}$ in the first $24 \mathrm{~h}$ of ICU admission.

Results: Hypothermia was identified in 186 patients and was independently associated with mortality. Levels of proinflammatory and anti-inflammatory cytokines were not different between groups. Hypothermia was also not associated with an altered response to ex vivo stimulation with lipopolysaccharide in a subset of 15 patients. Risk factors for hypothermia included low body mass index, hypertension and chronic cardiovascular insufficiency. Levels of the endothelial activation marker fractalkine were increased during the first 4 days of ICU stay.

Conclusions: Hypothermia during sepsis is independently associated with mortality, which cannot be attributed to alterations in the host immune responses that were measured in this study. Given that risk factors for hypothermic sepsis are mainly cardiovascular and that the endothelial activation marker fractalkine increased in hypothermia, these findings may suggest that vascular dysfunction plays a role in hypothermic sepsis.
\end{abstract}

Keywords: Hypothermia, Sepsis, Mortality, Risk factors, Host response, Fractalkine

\section{Background}

Sepsis is the consequence of a dysregulated immune response to infection, involving both proinflammatory and anti-inflammatory components, and a highly activated endothelium, resulting in increased vascular permeability, organ failure and shock [1]. Fever and hypothermia are both hallmark characteristics of sepsis [2]. Hypothermia is observed in $9-35 \%$ of patients with sepsis [3, 4]. Whereas fever is generally considered beneficial for patients, hypothermia is independently

\footnotetext{
* Correspondence: m.harmon@amc.uva.nl

${ }^{\dagger}$ Equal contributors

${ }^{2}$ Department of Intensive Care, Academic Medical Center, University of

Amsterdam, Amsterdam, The Netherlands

Full list of author information is available at the end of the article
}

associated with increased mortality [4]. However the etiology of hypothermia during sepsis is poorly understood.

Studies attempting to elucidate the hypothermic response in sepsis have focused on a hypothesized lack of proinflammatory cytokines, in particular interleukin (IL)-6 and tumor necrosis factor (TNF)- $\alpha$, which are the main mediators of fever. However, these studies could not demonstrate that a depression of the proinflammatory response is associated with hypothermia in sepsis $[5,6]$. Anti-inflammatory cytokines such as IL-10, which possess antipyretic properties in humans [7] and animals [8], have not been studied before in hypothermic patients with sepsis. An excessive anti-inflammatory response could potentially explain hypothermia [9] and 
associated lymphopenia, which was recently found in hypothermic patients with sepsis [10].

Other mechanisms have yet to be explored in hypothermic patients with sepsis. Endothelial dysfunction could also play a role in the development of hypothermia, as generalized peripheral vasodilation and loss of endothelial integrity during sepsis may result in heat loss by hampering the body's ability to regulate its core temperature $[11,12]$.

The aim of this current prospective observational study was to determine if hypothermia is independently associated with 90 -day mortality. We subsequently characterized the host immune response in patients with hypothermic sepsis, by determining both proinflammatory and anti-inflammatory cytokines, and whole blood ex vivo responsiveness to lipopolysaccharide (LPS). We also measured markers of endothelial activation and integrity. Finally, we studied risk factors for hypothermic sepsis in an attempt to find potential new insights into the etiology of hypothermia in sepsis. Understanding the etiology of hypothermic sepsis may contribute to the identification of potential targets for future interventions.

\section{Methods}

\section{Study design, patients and definitions}

From January 2011 through July 2013, consecutive patients presenting to the mixed intensive care units (ICU) of two Dutch tertiary teaching hospitals (Academic Medical Center in Amsterdam and University Medical Center in Utrecht) were included. Medical Ethical Committees of both centers approved an opt-out consent method (IRB no.10-056C). Data and plasma samples were prospectively collected as part of the Molecular Diagnosis and Risk Stratification of Sepsis (MARS) project (ClinicalTrials.gov identifier NCT01905033) [13, 14]. A group of trained investigators collected clinical data. The plausibility of infection was scored post hoc, and classified on a 4point scale (none, possible, probable or definite) $[15,16]$, as described in detail previously [14]. Shock was defined as hypotension requiring treatment with vasopressors at a dose of $0.1 \mathrm{mcg} / \mathrm{kg} / \mathrm{min}$ during at least $50 \%$ of the day. Acute kidney injury (AKI) and acute lung injury (ALI) were scored using pre-set criteria [17, 18]. Blood samples were collected in EDTA tubes, centrifuged and stored until further analysis.

We selected patients with sepsis, diagnosed within $24 \mathrm{~h}$ of admission, defined as a having definite or probable infection [14], combined with at least one parameter of inflammatory dysfunction, hemodynamic dysfunction, organ dysfunction or deranged tissue perfusion (derived from the 2001 International Sepsis Definitions Conference [2]). Patients with immunodeficiency disorders, use of corticosteroids, immunosuppressive or antineoplastic drugs were excluded. To exclude iatrogenic hypothermia, readmitted patients, patients undergoing active cooling and patients transferred from another ICU or operating room (OR) were also excluded.

To control for body temperatures that may have been inadvertently entered in the database (i.e. a rectal sensor that has been displaced and is exposed to ambient temperature), patients with unreliable measurements of temperature (below $33{ }^{\circ} \mathrm{C}$ ) were not included. Also, patients with a missing minimum temperature were not included. Temperature was measured using a rectal, nasal, inguinal or tympanic temperature probe. Core temperatures were used in preference to inguinal or tympanic measurements. The threshold for hypothermia was set at $36{ }^{\circ} \mathrm{C}$, based on previously used cutoffs $[10,19]$. Daily (at admission and at 6. a.m. thereafter) leftover EDTA coagulated plasma (obtained from blood drawn for patient care) was stored within $4 \mathrm{~h}$ at $-80{ }^{\circ} \mathrm{C}$. Samples were drawn prior to rewarming patients.

\section{Plasma biomarker measurements}

TNF- $\alpha$, IL-1 $\beta$, IL-6, IL-8, IL-10, IL-13, soluble intercellular adhesion molecule (ICAM)-1, fractalkine and soluble E-selectin were measured using FlexSet cytometric bead arrays (BD Bioscience, San Jose, CA, USA) using FACSCalibur (Becton Dickenson, Franklin Lakes, NJ, USA). Angiopoietin-1 and angiopoietin-2 (R\&D systems, Abingdon, UK) were measured by Luminex multiplex assay using BioPlex 200 (BioRad, Hercules, CA). Normal biomarker values were acquired from EDTA plasma from 27 age-matched and gender-matched healthy volunteers, from whom written informed consent was obtained.

The lower limits of detection for the immune assays were: $0.9 \mathrm{pg} / \mathrm{mL}$ for TNF- $\alpha, 1.3 \mathrm{pg} / \mathrm{mL}$ for IL- $1 \beta, 0.9 \mathrm{pg} /$ $\mathrm{mL}$ for IL-6, $1.3 \mathrm{pg} / \mathrm{mL}$ for IL-8, $0.8 \mathrm{pg} / \mathrm{mL}$ for IL-10, $0.7 \mathrm{pg} / \mathrm{mL}$ for IL-13, $3.1 \mathrm{pg} / \mathrm{mL}$ for soluble E-selectin, $6.3 \mathrm{pg} / \mathrm{mL}$ for soluble ICAM- $1,4.0 \mathrm{pg} / \mathrm{mL}$ for fractalkine, $0.2 \mathrm{pg} / \mathrm{mL}$ for angiopoietin- 1 and $1.8 \mathrm{pg} / \mathrm{mL}$ for angiopoietin-2.

\section{Whole blood stimulations}

In a random subset of 15 patients, whole blood was stimulated ex vivo with LPS on day 1 of ICU admission, as previously described [20]. Heparin-anticoagulated blood was stimulated for $3 \mathrm{~h}$ at $37{ }^{\circ} \mathrm{C}$ in pyrogen-free RPMI 1640 (Life Technologies, Bleiswijk, the Netherlands) with or without $100 \mathrm{ng} / \mathrm{mL}$ ultrapure LPS (from Escherichia coli 0111:B4; InvivoGen, Toulouse, France). TNF- $\alpha$ and IL-1 $\beta$ were measured in supernatants using a cytometric bead array assay (BD Biosciences, San Jose, CA, USA). Cytokine release was calculated as the difference in cytokine levels in samples incubated with and without LPS. The medical ethical committee of the Academic Medical Center in Amsterdam gave ethical approval for the study (number NL34294.018.10). Written informed consent was obtained 
from all patients, or their legal representative, and from healthy volunteers.

\section{Statistical analysis}

All analyses were performed in R (version 3.1.1). Student's $t$ test or the Wilcoxon rank-sum test, and the chi-square test were used to compare groups. To study factors independently associated with developing hypothermia, we performed multivariable logistic regression. Pre-ICUadmission patient characteristics that were deemed relevant or were associated with hypothermia in univariate analysis $(P<0.2)$ were included in the model. A backward selection procedure using the Akaike information criterion (AIC) including 1000 bootstrap replicates was applied (R-package "rms") to identify risk factors for hypothermia. Age was forced into the model because we considered it an important confounder for all factors incorporated in the model, and because it is associated with an altered temperature response $[4,21]$.

Multivariable logistic regression was used to establish the independent association between hypothermia and 90-day mortality. The Acute Physiology and Chronic Health Evaluation (APACHE) IV score was included in the model to adjust for severity of disease at ICU admission. Age, body mass index (BMI), admission type and source of infection were a priori considered potential clinically relevant confounders. Next, risk factors for hypothermia from logistic regression analyses were investigated as confounders of mortality. Significant variables were retained in the model, based on $10 \%$ change in estimate. In order to determine whether hypothermia was associated with biomarker response irrespective of severity of disease, hypothermic patients were 1:1 matched to nonhypothermic patients according to APACHE IV scores, using "optimal matching" with R-package "MatchIt". $P<0.05$ was considered statistically significant.

\section{Results}

\section{Epidemiology of hypothermic sepsis}

The selection of study patients is presented in Additional file 1: Figure S1. From a total of 525 patients, 186 patients (35.4\%) were hypothermic during the first $24 \mathrm{~h}$ of admission. Patient characteristics are shown in Table 1. Mean body temperature in the first $24 \mathrm{~h}$ was significantly lower in hypothermic versus nonhypothermic patients (median $36.3{ }^{\circ} \mathrm{C}$ and $37.3{ }^{\circ} \mathrm{C}$ respectively). Mean age in hypothermic patients was significantly higher and BMI was lower. Hypothermic patients suffered more frequently from cardiovascular disease including chronic cardiovascular insufficiency, hypertension and cerebrovascular disease. Hypothermic patients were most often admitted from the emergency department. Also, a significantly higher proportion of patients with hypothermia had a urinary tract infection. We observed no differences in causative organisms (Additional file 1: Table S1). Hypothermic patients were more seriously ill, as reflected by higher APACHE IV and Sequential Organ Failure Assessment (SOFA) scores and increased incidence of AKI (and requirement of renal replacement therapy). In line with this, patients with hypothermia had higher maximum white blood cell counts, longer prothrombin times and increased creatinine and lactate levels.

\section{Risk factors for hypothermic sepsis}

Multivariable analysis was performed to determine whether patient factors were independently associated with hypothermia. The initial model contained age, BMI, cerebrovascular disease, chronic cardiovascular insufficiency, hypertension, chronic renal insufficiency, site of infection and admission origin (Additional file 1: Table S2). Interestingly, hypertension (adjusted odds ratio (aOR) $1.98,95 \%$ CI 1.30-3.02) and chronic cardiovascular insufficiency (aOR 3.27, 95 \% CI 1.25-8.50) were associated with hypothermia. BMI was inversely correlated with hypothermia (aOR 0.96, 95 \% CI 0.93-0.99). Age was not independently associated with hypothermia (aOR 1.01, 95 \% CI 0.999-1.03).

\section{Hypothermia on admission is associated with increased mortality}

ICU and hospital mortality were significantly higher in septic patients with hypothermia (Additional file 1: Table S3). There were differences in mortality at 30, 60 and 90 days and at 1 year after ICU admission (Fig. 1 and Additional file 1: Table S3). There was an increased incidence of AKI during admission in patients with hypothermia. There was no difference in the incidence of ICU-acquired infections. Multivariable logistic regression including APACHE IV scores was performed to determine if hypothermia was independently associated with mortality. Site of infection was a confounder in our study and thus was retained in the model (Additional file 1: Table S4). Hypothermia was independently associated with an increased risk of death at 90 days (aOR 2.08, 95 \% CI $1.38-3.16)$.

\section{Hypothermic sepsis is not associated with altered anti-} inflammatory or proinflammatory cytokine plasma levels Levels of IL-13 were undetectable or low in the majority of patients and were not different between groups. Levels of IL-10 were increased in patients with sepsis compared to healthy subjects; however, there was no association with the presence of hypothermia (Fig. 2).

The proinflammatory cytokines TNF- $\alpha$ and IL- $1 \beta$ were also undetectable or low in the majority of patients and were not different between groups. IL- 6 and IL-8 levels were increased in patients with sepsis; 
Table 1 Baseline characteristics of sepsis patients with and without hypothermia during the first $24 \mathrm{~h}$ of admission

\begin{tabular}{|c|c|c|c|}
\hline \multirow{3}{*}{$\overline{\text { Demographics }}$} & \multirow{2}{*}{$\begin{array}{l}\text { Hypothermia } \\
N=186\end{array}$} & \multirow{2}{*}{$\begin{array}{l}\text { No hypothermia } \\
N=339\end{array}$} & \multirow[t]{2}{*}{$P$} \\
\hline & & & \\
\hline & & & \\
\hline Age, years, mean (SD) & $65.0(13.8)$ & $61.1(15.6)$ & 0.004 \\
\hline Gender, male, $n(\%)$ & $114(61.3)$ & $206(60.8)$ & 0.94 \\
\hline $\mathrm{BMI}, \mathrm{kg} / \mathrm{m}^{2}$, mean (SD) & $25.6(5.7)$ & $26.7(6.7)$ & 0.04 \\
\hline \multicolumn{4}{|l|}{ Comorbidities } \\
\hline Charlson score, median (IQR) & $5(3-6)$ & $4(2-6)$ & 0.01 \\
\hline Cerebrovascular disease, $n$ (\%) & $28(15.1)$ & $27(8)$ & 0.01 \\
\hline Chronic cardiovascular insufficiency, $n$ (\%) & $13(7)$ & $7(2.1)$ & 0.009 \\
\hline Chronic renal insufficiency, $n$ (\%) & $26(14)$ & $32(9.4)$ & 0.15 \\
\hline Congestive heart failure, $n(\%)$ & $8(4.3)$ & $17(5)$ & 0.84 \\
\hline COPD, $n(\%)$ & $29(15.6)$ & $61(18)$ & 0.55 \\
\hline Diabetes mellitus, $n(\%)$ & $42(22.6)$ & $67(19.8)$ & 0.51 \\
\hline Hypertension, $n(\%)$ & $73(39.2)$ & $87(25.7)$ & 0.003 \\
\hline Liver cirrhosis, $n(\%)$ & $7(3.8)$ & $6(1.8)$ & 0.23 \\
\hline Peripheral vascular disease, $n(\%)$ & $25(13.4)$ & $44(13)$ & 0.90 \\
\hline \multicolumn{4}{|l|}{ Admission } \\
\hline Admission type, medical, $n$ (\%) (\%) & $163(87.6)$ & $298(87.9)$ & 0.55 \\
\hline Admission origin, emergency department, $n$ (\%) (\%) & $74(39.8)$ & $99(29.2)$ & 0.04 \\
\hline medium care, $n(\%)$ & $26(14)$ & $47(13.9)$ & \\
\hline ward, $n(\%)$ & $86(46.2)$ & $193(56.9)$ & \\
\hline \multicolumn{4}{|l|}{ Site of infection } \\
\hline Pulmonary, $n$ (\%) & $79(42.5)$ & $161(47.5)$ & 0.28 \\
\hline Abdominal, $n(\%)$ & $29(15.6)$ & $65(19.2)$ & 0.34 \\
\hline Urinary tract, $n(\%)$ & $32(17.2)$ & $33(9.7)$ & 0.02 \\
\hline Other, $n(\%)$ & $18(9.7)$ & $44(13)$ & 0.31 \\
\hline Co-infection, $n(\%)$ & $28(15.1)$ & $36(10.6)$ & 0.15 \\
\hline \multicolumn{4}{|l|}{ Severity of disease first $24 \mathrm{~h}$} \\
\hline Mean temperature first $6 \mathrm{~h}$, median (IQR) & $36.1(35.4-37)$ & $37.2(36.5-38)$ & $<0.0001$ \\
\hline Mean temperature first $24 \mathrm{~h}$, median (IQR) & $36.3(35.8-36.9)$ & $37.3(36.8-37.8)$ & $<0.0001$ \\
\hline APACHE IV score, median (IQR) ${ }^{\mathrm{a}}$ & $82(67-103)$ & $71(58-86)$ & $<0.0001$ \\
\hline SOFA score, median (IQR) & $8(5-10)$ & $7(4-8)$ & $<0.001$ \\
\hline Acute kidney injury, $n$ (\%) & $92(49.5)$ & $118(34.8)$ & 0.002 \\
\hline Renal replacement therapy, n (\%) & $32(17.1)$ & $21(6.2)$ & $<0.001$ \\
\hline Acute lung injury, $n(\%)$ & $49(26.3)$ & $99(29.2)$ & 0.57 \\
\hline Shock, $n(\%)$ & $74(39.8)$ & $106(31.3)$ & 0.06 \\
\hline \multicolumn{4}{|l|}{ Clinical laboratory parameters first $24 \mathrm{~h}$} \\
\hline WBC count max. $\left(\times 10^{\wedge} 9 / \mathrm{L}\right)$, median (IQR) & $16.1(10.9-25.5)$ & $14.9(10-19.2)$ & 0.02 \\
\hline WBC count min. $(\times 10 \wedge 9 / L)$, median $(\mathrm{IQR})$ & $12.6(7.1-19.1)$ & $12.2(7.7-16.2)$ & 0.25 \\
\hline Platelets min. $\left(\times 10^{\wedge} 9 / \mathrm{L}\right)$, median (IQR) & $189(120-264)$ & $199(131-283)$ & 0.27 \\
\hline Lactate max. (mmol/L), median (IQR) & $3.2(1.6-6.5)$ & $2.5(1.6-4.1)$ & 0.009 \\
\hline Prothrombin time max. (s), median (IQR) & $16.5(14.1-20.7)$ & $15(12.6-18.2)$ & 0.0001 \\
\hline Creatinin max. $(\mu \mathrm{mol} / \mathrm{L})$, median (IQR) & $121(80-209)$ & $97(68-162)$ & $<0.001$ \\
\hline C-reactive protein (mg/L), median (IQR) & $146(82-258)$ & $174(98-263)$ & 0.25 \\
\hline
\end{tabular}

${ }^{\mathrm{a}}$ Temperature not included in score. ${ }^{\mathrm{b}} \mathrm{Central}$ nervous system not included in score due to large number of sedated patients. APACHE Acute Physiology And Chronic Health Evaluation, COPD chronic obstructive pulmonary disease, IQR interquartile range, SD standard deviation, SOFA Sequential Organ Failure

Assessment, WBC white blood cell 


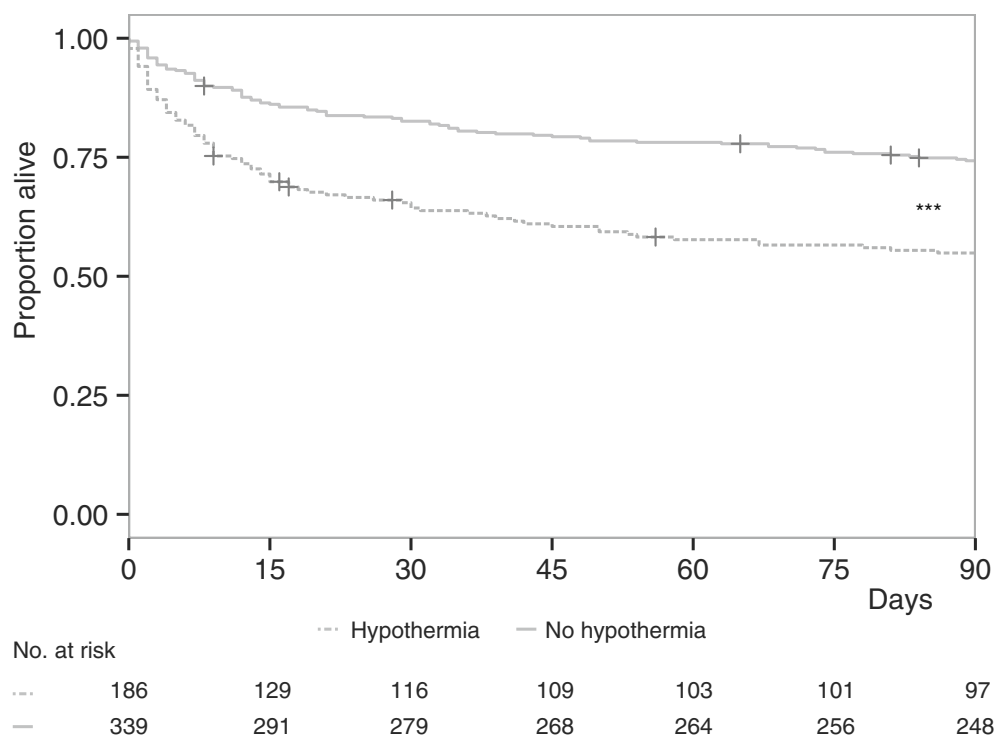

Fig. 1 Survival curve in patients with and without hypothermia during the first $24 \mathrm{~h}$ of ICU admission. Kaplan-Meier plot of survival time up to 90 days after ICU admission. ${ }^{* *} P<0.001$

however, there was also no association with the presence of hypothermia (Fig. 2).

\section{Hypothermia does not affect leukocyte responsiveness upon ex vivo stimulation}

As hypothermia has been postulated to be an early clinical predictor of sepsis-induced immunosuppression [10], we investigated the association between hypothermia and the responsiveness of circulating immune effector cells to LPS, a marker of sepsis-induced immunosuppression [22].
Whole blood from 15 patients with sepsis, of whom 5 had hypothermia, was stimulated ex vivo and compared with blood from 18 healthy age- and gender-matched volunteers. Clinical characteristics of patients with sepsis are displayed in Additional file 1: Table S5. Patients with sepsis had a reduced capacity to release TNF- $\alpha$ and IL-1 $\beta$ upon LPS stimulation compared to healthy controls (Fig. 3). However, no differences in cellular responsiveness were observed between hypothermic and nonhypothermic patients with sepsis.
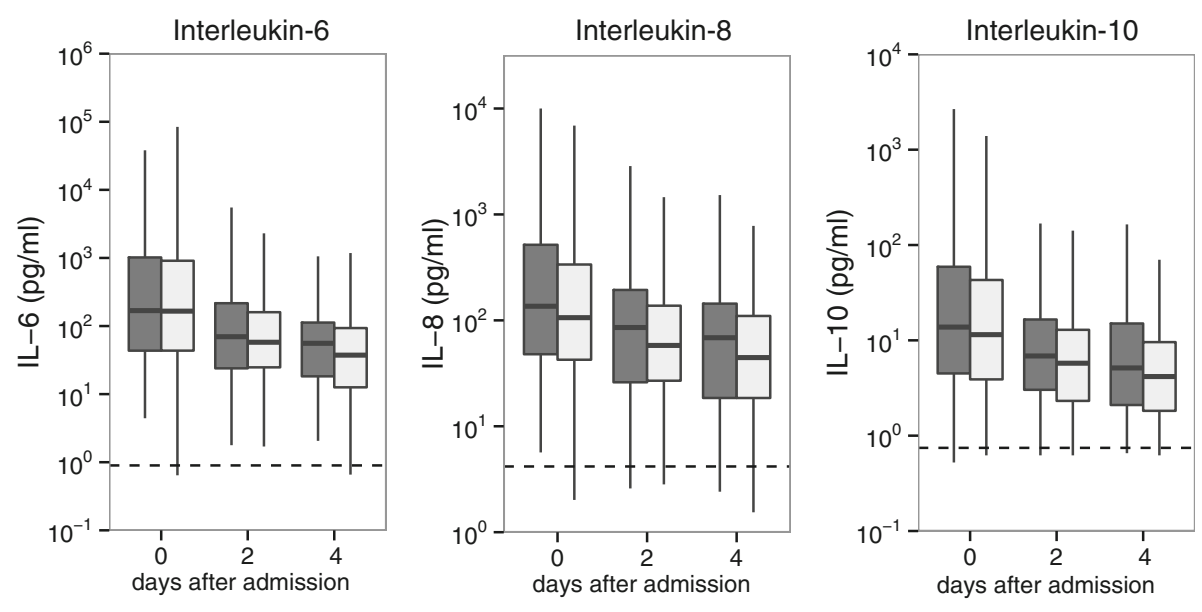

Hypothermia

追 No hypothermia - - Healthy subjects

Fig. 2 Plasma cytokine levels in patients with sepsis, stratified according to the presence of hypothermia. Box and whisker diagrams depict the median and lower quartile, upper quartile and respective 1.5 IQR as whiskers. Dashed lines represent median levels in healthy volunteers. Differences between patient groups were not significant 


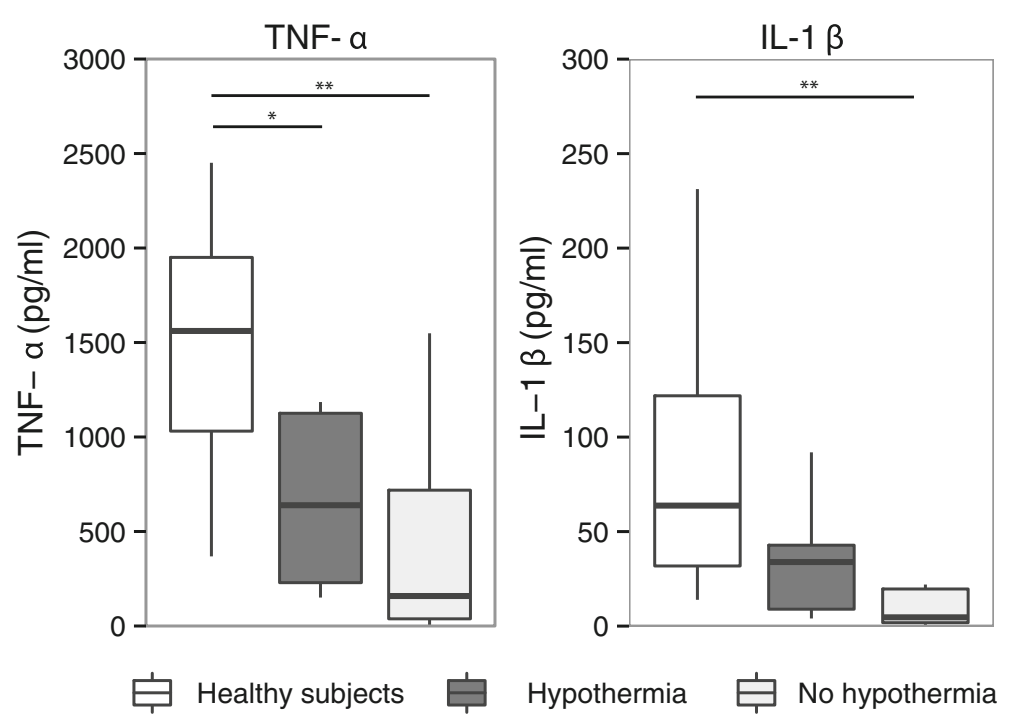

Fig. 3 Whole blood leukocyte responsiveness to lipopolysaccharide (LPS) stratified according to the presence of hypothermia. Responsiveness of whole blood leukocytes to LPS was reduced compared to healthy subjects $(n=18)$, but was not different between hypothermic $(n=5)$ and nonhypothermic $(n=10)$ patients with sepsis. Box and whisker diagrams depict the median and lower quartile, upper quartile, and their respective 1.5 IQR as whiskers. ${ }^{*} P<0.05,{ }^{* *} P<0.01$

\section{Hypothermia is associated with increased plasma levels of the endothelial cell activation marker fractalkine}

All markers of endothelial dysfunction were higher in patients with sepsis compared to healthy controls, except angiopoetin-1, which was lower (Fig. 4). Angiopoietin-2 and the ratio of angiopoietin-2/angiopoietin-1 were higher in hypothermic patients on day 2 compared to nonhypothermic patients with sepsis. This difference was not present at the other time points. Strikingly, levels of fractalkine, an endothelial-cell-derived chemokine, were substantially higher in hypothermic versus nonhypothermic patients on the day of admission (Fig. 4). These differences persisted on days 2 and 4 after admission.

To determine whether the higher levels of fractalkine in the hypothermic group were due to differences in disease severity, every hypothermic patient was matched to a nonhypothermic patient with a comparable APACHE IV score. Patient characteristics of the matched cohort are shown in Additional file 1: Table S6. In the subsequent analysis fractalkine remained significantly higher in patients with hypothermia (median on admission $28.5 \mathrm{pg} / \mathrm{mL}$ vs $20.8 \mathrm{pg} / \mathrm{mL}, P=0.005$, median on day 2 18.6 vs $30.8 \mathrm{pg} / \mathrm{mL}, P=0.001$ and median on day 417.1 vs $29.0 \mathrm{pg} / \mathrm{mL}, P=0.001$ ), whereas the other host response biomarkers, including angiopoietin-2 and the ratio of angiopoeietin-2/angiopoietin-1, were not different between groups. There were no differences in soluble ICAM-1, soluble E-selectin or angiopoietin-1 between hypothermic and nonhypothermic patients.

\section{Discussion}

Hypothermia at ICU admission is independently associated with adverse outcome in patients with sepsis. In this extensive evaluation of the immune response in hypothermic sepsis, the host immune response was not altered in patients with hypothermia compared to nonhypothermic patients. The endothelial activation marker fractalkine was persistently higher in hypothermic sepsis, irrespective of disease severity. In addition, low BMI, hypertension and cardiovascular insufficiency were identified as risk factors for hypothermic sepsis. Taken together, these data suggest that vascular dysfunction could play a role in hypothermic sepsis.

An excessive anti-inflammatory response has been proposed as a mechanism for hypothermia [9]. In line with this, a recent study showed increased immunosuppression in hypothermic patients [10], thereby potentially accounting for the association with adverse outcome $[3-5,10]$. In contrast, we found no difference in either proinflammatory or anti-inflammatory cytokines between hypothermic and nonhypothermic patients, even after correction for disease severity. These data are in line with a study in hypothermic patients showing no difference in circulating levels of proinflammatory cytokines [5] and extend these data by showing that levels of anti-inflammatory cytokines are also not affected by hypothermia. Moreover, whole blood stimulations resulted in similar cytokine release in hypothermic vs nonhypothermic patients. Therefore a mechanism for hypothermia directly involving antiinflammatory cytokines seems unlikely. Rather, these data 

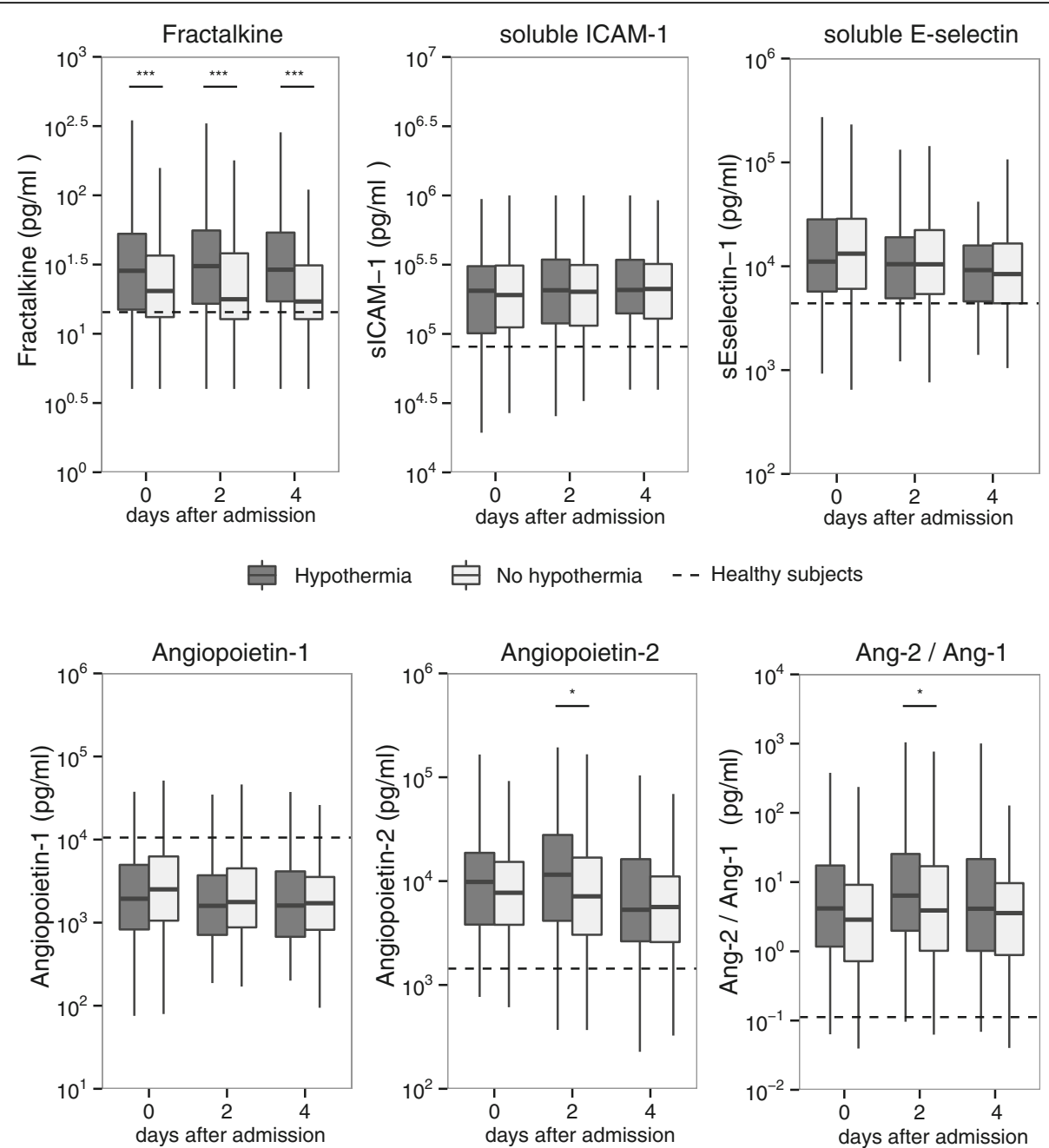

Fig. 4 Endothelial cell activation in patients with sepsis, stratified according to the presence of hypothermia. Box-and-whisker diagrams depict the median and lower quartile, upper quartile and their respective 1.5 IQR as whiskers. Dashed lines represent the median in 27 healthy volunteers. ICAM-1 intercellular adhesion molecule-1. Note: soluble ICAM-1 is also derived from leukocytes. ${ }^{* * *} P<0.001,{ }^{*} P<0.05$

suggest that hypothermic patients do not suffer from increased immunosuppression. In support of this, the incidence of ICU-acquired infections was similar between groups, as found before in sepsis [23]. Of note, according to standard cell stimulation protocols experiments were performed ex vivo at an incubation temperature of $37^{\circ} \mathrm{C}$. If whole blood stimulations had been performed at a lower temperature to simulate the temperature of hypothermic patients, one could expect that overall the reactivity of cells in terms of cytokine production might have been slightly higher [24].

In this systematic study of risk factors for hypothermia during sepsis we identified several interesting associations. BMI was inversely correlated with hypothermia. A physiological explanation is that increased body mass likely slows the dissipation of heat from the body. As low BMI has been associated with poor outcome in the ICU [25], the relationship between hypothermia and BMI and their combined role on outcome is unclear. Leptin, released from adipose tissue, has anti-inflammatory properties and may also mediate the hypothermic response, providing a possible link between the two [26].

Of interest, we also identified hypertension and chronic cardiovascular insufficiency as risk factors. Patients with cardiovascular disease may be hampered in raising or maintaining core temperature by a dysfunction in autonomic mechanisms such as increased heart rate and blood pressure, and by shifting capillary blood flow from cutaneous to deep vascular beds [27]. Alternatively, the association between hypothermia and cardiovascular conditions may reflect the importance of an intact endothelial function in maintaining body temperature during sepsis.

Interestingly, systemic fractalkine levels were significantly higher in hypothermic patients compared to nonhypothermic patients, and this difference was maintained after correcting for disease severity. Fractalkine is a 
chemokine that has been implicated as a mediator in a diverse spectrum of inflammatory conditions [28]. In critically ill patients with sepsis, increased fractalkine is associated with adverse outcome [28]. Arterial and capillary endothelial cells have been identified as an important source of fractalkine during endotoxemia [29]. Also, levels of angiopoetin-2 and the ratio of angiopoietin-2/angiopoietin-1, which indicate impaired vascular integrity, were increased in the hypothermic patients compared to the nonhypothermic patients, albeit transiently. Taken together with the presence of mainly cardiovascular risk factors in patients with hypothermia, our data suggest that the endothelium may somehow be implicated in hypothermia through an as yet unknown mechanism. Although the current data do not establish a causal link between fractalkine and hypothermia, and the association between hypothermia and fractalkine in a population with significantly increased disease severity warrants further validation, the increased levels of fractalkine in hypothermia are intriguing and a detailed study of the role of the endothelium, in particular fractalkine, is warranted.

There are several shortcomings to this study. First, the timing and method of temperature measurement was not standardized. Although this could have led to increased variability in this study, we believe this effect will be limited due to the fact that core temperature measurements are standard practice in our ICUs. Second, blood sampling did not exactly coincide with timing of the temperature measurement. Although this might have diluted the results, a single instance of hypothermic temperature within $24 \mathrm{~h}$ significantly increases mortality, and we feel that the blood sampling does not necessarily need to be at exactly the same time as the hypothermic measurement to characterize this group. Third, results from this study are not applicable to all patients with sepsis, as we excluded patients with decreased ability to mount an adequate host response (those on steroids or those with immunodeficiency) and patients at risk of iatrogenic hypothermia (patients admitted directly from the OR). Multiple testing can cause confounding. However after Bonferroni correction fractalkine remained significantly associated with hypothermia. Also, as fractalkine was significantly elevated at all time points and remained significant after matching for disease severity, we consider these results to be valid. Last, this is an observational study and cause-effect relationships cannot be established due to the nature of this study design.

\section{Conclusions}

In conclusion, hypothermia during sepsis is independently associated with 90-day mortality. However, neither the etiology of hypothermia or increased mortality due to hypothermia are explained by a dysfunctional hostimmune response. Low BMI, hypertension and chronic cardiovascular insufficiency are risk factors for hypothermic sepsis. Hypothermia is associated with increased levels of the endothelial-derived biomarker fractalkine. The functional role of fractalkine and the endothelium in the context of hypothermic sepsis requires further study.

\section{Additional file}

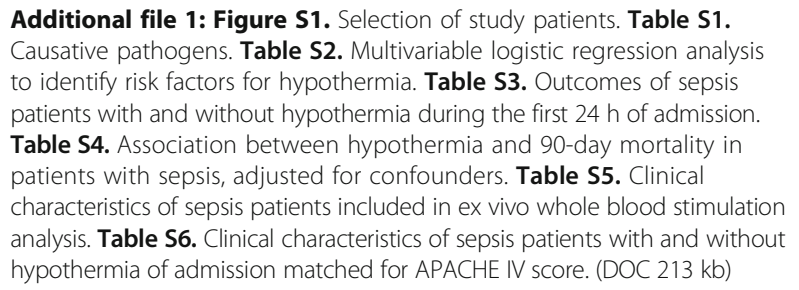

\section{Abbreviations}

AIC: Akaike information criterion; AKI: acute kidney injury; ALI: acute lung injury; aOR: adjusted odds ratio; APACHE: Acute Physiology and Chronic Health Evaluation; BMI: body mass index; Cl: confidence interval; ICAM: intercellular adhesion molecule; ICU: intensive care unit; IL: interleukin; LPS: lipopolysaccharide; OR: operating room; SOFA: Sequential Organ Failure Assessment; TNF: tumor necrosis factor

\section{Acknowledgments}

The authors acknowledge all members of the MARS consortium for the participation in data collection and especially acknowledge: Friso M. de Beer, MD, Lieuwe D. J. Bos, PhD (Department of Intensive Care, Academic Medical Center, University of Amsterdam), Jos F. Frencken, MD (Department of Intensive Care Medicine and Julius Center for Health Sciences and Primary Care, University Medical Center Utrecht, Utrecht, the Netherlands), Gerie J. Glas, MD, Roosmarijn T. M. van Hooijdonk, MD, PhD (Department of Intensive Care, Academic Medical Center, University of Amsterdam), Mischa A. Huson, MD (Center for Experimental and Molecular Medicine, Academic Medical Center, University of Amsterdam), Peter M.C. Klein Klouwenberg, MD, PharmD, PhD, David S. Y. Ong, MD, PharmD (Department of Intensive Care Medicine, Julius Center for Health Sciences and Primary Care and Department of Medical Microbiology, University Medical Center Utrecht, Utrecht, the Netherlands), Laura R. A. Schouten, MD (Department of Intensive Care, Academic Medical Center, University of Amsterdam), Marleen Straat, MD, Esther Witteveen, MD, and Luuk Wieske, MD, PhD (Department of Intensive Care, Academic Medical Center, University of Amsterdam).

\section{Funding}

This work was supported by the Center for Translational Molecular Medicine (CTMM) (www.ctmm.nl), project MARS (grant 04l-201).

\section{Availability of data and materials}

The datasets supporting the results of this article are available on request, which may be addressed to m.a.wiewel@amc.uva.nl.

\section{Authors' contributions}

MAW, MBH, TvdP, NPJ and WJW designed the study. MAW, MBH, LAvV, BPS, AJH and AHZ performed the analyses. MAW, LAVV, BPS, AJH, JH, OC, MJS and MJB collected the data. MAW, MBH, NPJ and WJW drafted the manuscript. All authors critically reviewed the manuscript. All authors read and approved the final version of this manuscript.

Competing interests

The authors declare that there are no competing interests.

Consent for publication

All the co-authors approve the publication of this manuscript. 


\section{Ethics approval and consent to participate}

Medical Ethical Committees of the Academic Medical Center in Amsterdam and University Medical Center in Utrecht approved an opt-out consent method for this study (IRB no.10-056C).

\section{Author details}

'Center for Experimental and Molecular Medicine, Academic Medical Center, University of Amsterdam, Amsterdam, The Netherlands. ${ }^{2}$ Department of Intensive Care, Academic Medical Center, University of Amsterdam, Amsterdam, The Netherlands. ${ }^{3}$ Clinical Epidemiology Biostatistics and Bioinformatics, Academic Medical Center, University of Amsterdam, Amsterdam, The Netherlands. ${ }^{4}$ Division of Infectious Diseases, University Medical Center Utrecht, Utrecht, The Netherlands. ${ }^{5}$ Department of Intensive Care Medicine, University Medical Center Utrecht, Utrecht, The Netherlands. ${ }^{6}$ Department of Medical Microbiology, University Medical Center Utrecht, Utrecht, The Netherlands. ${ }^{7} J u l i u s$ Center for Health Sciences and Primary Care, University Medical Center Utrecht, Utrecht, The Netherlands.

\section{Received: 31 May 2016 Accepted: 26 September 2016}

\section{Published online: 14 October 2016}

\section{References}

1. Angus DC, van der Poll T. Severe sepsis and septic shock. N Engl J Med. 2013;369(9):840-51.

2. Levy MM, Fink MP, Marshall JC, Abraham E, Angus D, Cook D, Cohen J, Opal SM, Vincent JL, Ramsay G, et al. 2001 SCCM/ESICM/ACCP/ATS/SIS International Sepsis Definitions Conference. Intensive Care Med. 2003; 29(4):530-8.

3. Clemmer TP, Fisher Jr CJ, Bone RC, Slotman GJ, Metz CA, Thomas FO. Hypothermia in the sepsis syndrome and clinical outcome. The Methylprednisolone Severe Sepsis Study Group. Crit Care Med. 1992;20(10): 1395-401.

4. Kushimoto S, Gando S, Saitoh D, Mayumi T, Ogura H, Fujishima S, Araki T, Ikeda H, Kotani J, Miki Y, et al. The impact of body temperature abnormalities on the disease severity and outcome in patients with severe sepsis: an analysis from a multicenter, prospective survey of severe sepsis. Crit Care. 2013;17(6):R271.

5. Marik PE, Zaloga GP. Hypothermia and cytokines in septic shock. Norasept II Study Investigators. North American study of the safety and efficacy of murine monoclonal antibody to tumor necrosis factor for the treatment of septic shock. Intensive Care Med. 2000;26(6):716-21.

6. Arons MM, Wheeler AP, Bernard GR, Christman BW, Russell JA, Schein R, Summer WR, Steinberg KP, Fulkerson W, Wright P, et al. Effects of ibuprofen on the physiology and survival of hypothermic sepsis. Ibuprofen in Sepsis Study Group. Crit Care Med. 1999;27(4):699-707.

7. Pajkrt D, Camoglio L, Tiel-van Buul MC, de Bruin K, Cutler DL, Affrime MB, Rikken G, van der Poll T, ten Cate JW, van Deventer SJ. Attenuation of proinflammatory response by recombinant human IL-10 in human endotoxemia: effect of timing of recombinant human IL-10 administration. J Immunol. 1997;158(8):3971-7.

8. Leon LR, Kozak W, Rudolph K, Kluger MJ. An antipyretic role for interleukin10 in LPS fever in mice. Am J Physiol. 1999;276(1 Pt 2):R81-9.

9. Leon LR. Hypothermia in systemic inflammation: role of cytokines. Front Biosci. 2004;9:1877-88.

10. Drewry AM, Fuller BM, Skrupky LP, Hotchkiss RS. The presence of hypothermia within 24 hours of sepsis diagnosis predicts persistent lymphopenia. Crit Care Med. 2015.

11. Mallet ML. Pathophysiology of accidental hypothermia. QJM. 2002;95(12): 775-85.

12. Romanovsky AA, Shido O, Sakurada S, Sugimoto N, Nagasaka T. Endotoxin shock: thermoregulatory mechanisms. Am J Physiol. 1996;270(4 Pt 2): R693-703.

13. Scicluna BP, Klein Klouwenberg PM, van Vught LA, Wiewel MA, Ong DS, Zwinderman AH, Franitza M, Toliat MR, Nurnberg P, Hoogendijk AJ, et al. A molecular biomarker to diagnose community-acquired pneumonia on intensive care unit admission. Am J Respir Crit Care Med. 2015;192(7):826-35.

14. Klein Klouwenberg PM, Ong DS, Bos LD, de Beer FM, van Hooijdonk RT, Huson MA, Straat M, van Vught LA, Wieske L, Horn J, et al. Interobserver agreement of Centers for Disease Control and Prevention criteria for classifying infections in critically ill patients. Crit Care Med. 2013;41(10):2373-8.
15. Garner JS, Jarvis WR, Emori TG, Horan TC, Hughes JM. CDC definitions for nosocomial infections, 1988. Am J Infect Control. 1988;16(3):128-40.

16. Calandra T, Cohen J. International Sepsis Forum definition of infection in the ICUCC. The International Sepsis Forum consensus conference on definitions of infection in the intensive care unit. Crit Care Med. 2005;33(7): $1538-48$.

17. Force ADT, Ranieri VM, Rubenfeld GD, Thompson BT, Ferguson ND, Caldwell E, Fan E, Camporota L, Slutsky AS. Acute respiratory distress syndrome: the Berlin definition. JAMA. 2012;307(23):2526-33.

18. Bellomo R, Ronco C, Kellum JA, Mehta RL, Palevsky P, Acute Dialysis Quality Initiative. Acute renal failure - definition, outcome measures, animal models, fluid therapy and information technology needs: the Second International Consensus Conference of the Acute Dialysis Quality Initiative (ADQI) Group. Crit Care. 2004;8(4):R204-12.

19. Peres Bota D, Lopes Ferreira F, Melot C, Vincent JL. Body temperature alterations in the critically ill. Intensive Care Med. 2004;30(5):811-6.

20. van Vught LA, Wiewel MA, Hoogendijk AJ, Scicluna BP, Belkasim-Bohoudi $H$, Horn J, Schultz MJ, van der Poll T. Reduced responsiveness of blood leukocytes to lipopolysaccharide does not predict nosocomial infections in critically ill patients. Shock. 2015;44(2):110-4.

21. Tiruvoipati R, Ong K, Gangopadhyay H, Arora S, Carney I, Botha J. Hypothermia predicts mortality in critically ill elderly patients with sepsis. BMC Geriatr. 2010;10:70.

22. Wiersinga WJ, van't Veer $C$, van den Pangaart PS, Dondorp AM, Day NP, Peacock SJ, van der Poll T. Immunosuppression associated with interleukin1R-associated-kinase-M upregulation predicts mortality in Gram-negative sepsis (melioidosis). Crit Care Med. 2009;37(2):569-76.

23. Laupland KB, Zahar JR, Adrie C, Minet C, Vesin A, Goldgran-Toledano D, Azoulay E, Garrouste-Orgeas M, Cohen Y, Schwebel C, et al. Severe hypothermia increases the risk for intensive care unit-acquired infection. Clin Infect Dis. 2012;54(8):1064-70.

24. Nerad JL, Griffiths JK, Van der Meer JW, Endres S, Poutsiaka DD, Keusch GT, Bennish M, Salam MA, Dinarello CA, Cannon JG. Interleukin-1 beta (IL-1 beta), IL-1 receptor antagonist, and TNF alpha production in whole blood. J Leukoc Biol. 1992;52(6):687-92.

25. Sakr Y, Alhussami I, Nanchal R, Wunderink RG, Pellis T, Wittebole $X$, Martin-Loeches I, Francois B, Leone M, Vincent $J$, et al. being overweight is associated with greater survival in ICU patients: results from the Intensive Care Over Nations Audit. Crit Care Med. 2015;43(12): 2623-32.

26. Steiner AA, Romanovsky AA. Leptin: at the crossroads of energy balance and systemic inflammation. Prog Lipid Res. 2007;46(2):89-107.

27. Saper CB. Neurobiological basis of fever. Ann NY Acad Sci. 1998;856:90-4.

28. Hoogendijk AJ, Wiewel MA, van Vught LA, Scicluna BP, Belkasim-Bohoudi H, Horn J, Zwinderman AH, Klein Klouwenberg PM, Cremer OL, Bonten MJ, et al. Plasma fractalkine is a sustained marker of disease severity and outcome in sepsis patients. Crit Care. 2015;19(1):412.

29. Sung MJ, Kim W, Ahn SY, Cho CH, Koh GY, Moon SO, Kim DH, Lee S, Kang $K P$, Jang $K Y$, et al. Protective effect of alpha-lipoic acid in lipopolysaccharide-induced endothelial fractalkine expression. Circ Res. 2005;97(9):880-90.

\section{Submit your next manuscript to BioMed Central and we will help you at every step:}

- We accept pre-submission inquiries

- Our selector tool helps you to find the most relevant journal

- We provide round the clock customer support

- Convenient online submission

- Thorough peer review

- Inclusion in PubMed and all major indexing services

- Maximum visibility for your research

Submit your manuscript at www.biomedcentral.com/submit
Biomed Central 